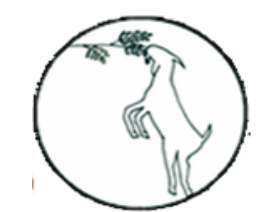

Agropecuária Científica no Semiárido

Centro de Saúde e Tecnologia Rural

http://revistas.ufcg.edu.br/acsa/index.php/ACSA/index

ISSN: $1808-6845$

DOI: http://dx.doi.org/10.30969/acsa.v16i4.1300

\title{
Avaliação dos impactos socioambientais causados pela mineração de caulim em Municípios do estado da Paraíba e Rio Grande do Norte
}

\author{
Raphael Augusto Almeida1 ${ }^{1}$ João Batista alves ${ }^{1 *}$
}

\begin{abstract}
Resumo: Os minerais apresentam importância socioeconômica que remonta o uso de determinados tipos de pedra como o sílex para fabricação de utensílios e armas. Novos materiais também são desenvolvidos a cada dia. Nesse sentido, a demanda por produtos minerais de diversas composições é necessária e dentre esses, pode-se referir aos não metálicos como o caulim. Entretanto, com a realização dos diversos tipos de atividades que compõem o processo de exploração mineral, vários impactos negativos são gerados e, em algumas situações, estas ações são irreversíveis ao meio ambiente e posteriormente à população, ao ponto de ainda não terem sido completamente mensurados. Diante disso, o objetivo deste trabalho é identificar os impactos socioambientais causados nas atividades de extração e beneficiamento do caulim nos municípios do Junco do Seridó e Assunção na Paraíba e Equador no Rio Grande do Norte. O presente trabalho utilizou-se da aplicação de questionário a uma amostra da população da zona rural residente no entorno das mineradoras, nos respectivos municípios. Teve como base a análise de conteúdo das respostas e se caracteriza como uma pesquisa quantitativa-qualitativa. Ao todo foram aplicados 30 questionários, 11 no município do Junco do Seridó-PB, 10 em Assunção-PB e 9 em Equador-RN. Foi possível identificar através do relato dos interlocutores, que há impactos como a emissão de poeira, prejuízos à flora e fauna. Verifica-se dessa forma que, na amostragem realizada, há geração de impactos que, em termos locais, podem gerar prejuízos superiores aos benefícios, pois, apesar da oferta de empregos, contudo, proporciona baixa renda aos trabalhadores.
\end{abstract}

Palavras-chaves: impactos mbientais, mineradoras, percepção, semiárido.

\section{Assessment of the socio-environmental impacts caused by the caulim mining in Municipalities of the state of Paraíba and Rio Grande do Norte}

\begin{abstract}
Minerals represent a socioeconomic significance that goes back to the use of certain types of stone such as flint in the utensils and weapons manufacture. New materials are also developed every day. In this sense, the demand for different compositions of mineral products is necessary and among these compositions are non-metallic minerals such as kaolin. However, with the various types of activities that are involved in the mineral exploration process, several negative impacts are generated and in some situations, these actions are irreversible to the environment and later to the population, to the point that they have not yet been fully measured. Therefore, the objective of this research is to identify the socioenvironmental impacts caused by the kaolin processing and extraction in the municipalities of Junco do Seridó and Assunção in the state of Paraíba and Equador in the state of Rio Grande do Norte. The present study used a questionnaire application to a sample of the rural population living in the vicinity of the mining companies, in the respective municipalities. This study was based on the content analysis of the responses and it is characterized as a quantitativequalitative research. Altogether 30 questionnaires were applied, 11 in the municipality of Junco do Seridó-PB, 10 in Assunção-PB and 9 in Equador-RN. It was possible to identify through the interlocutors report, that there are impacts such as dust emission, flora and fauna damage. In this way, it is verified in this sampling that there is generation of impacts and, in local terms, they can bring losses greater than the benefits, as there is a job growth, however, it provides low income to workers.
\end{abstract}

Keywords: environmental impacts, mining companies, perception, semiarid.

\section{INTRODUÇÃO}

Os minerais apresentam importância socioeconômica que remonta o uso de determinados tipos de pedra como o sílex para fabricação de utensílios e armas. No decorrer do tempo, novos metais foram sendo descobertos e usados para essas mesmas atividades, tais como o bronze, o cobre, a prata e o chumbo. Contudo, o uso de minerais como base para atividades humanas passou por um incremento sem precedentes no período da Revolução Industrial e não parou mais. Na contemporaneidade, a oferta de produtos nos mercados abarca uma

diversidade em quantidades cada vez maiores. Novos materiais também são desenvolvidos a cada dia. Nesse sentido, a demanda por produtos minerais de diversas composições é necessária e dentre esses, pode-se referir aos não metálicos como o caulim.

Em 2017, a produção mundial total de caulim foi de 36,6 milhões de toneladas (Mt), crescendo 4,3\% em relação a 2016, mantendo a liderança dos Estados Unidos com, aproximadamente, 5,5 Mt, seguido pela Alemanha (4,3 Mt), Índia (4,1 Mt), República Tcheca $(3,5 \mathrm{Mt})$. O Brasil permaneceu na $8^{\mathrm{a}}$ colocação, com

Recebido em 11/03/2020; Aceito para publicação em 08/06/2020

${ }^{1}$ Universidade Federal de Campina Grande

*e-mail: alvesjb@uol.com.br 
1,77 Mt. A produção interna total de caulim (bruto + beneficiado) em 2017, somou 819 milhões de reais, valor que vem subindo nos últimos 5 anos e é $48 \%$ superior ao registrado em 2013 (ANM, 2018). O Ministério de Minas e Energia do Brasil, em boletim técnico do ano de 2019, alega que a produção nacional em 2018 foi de 2 milhões de toneladas. No país, a atividade minerária é considerada uma das atividades econômicas mais antigas e tradicionais (BONFIM, 2017).

A sociedade utiliza e se beneficia dos recursos minerais. Essa ligação é necessária pelo fato de os minerais possuírem vários elementos vitais para existência do ser humano, desde o suporte básico para alimentação e abrigo, até o seu conforto, estendendose à saúde, transporte, educação e mercado de trabalho. Por causa da multiplicidade de uso destes bens naturais, a mineração é apontada como a atividade responsável pelo crescimento e desenvolvimento econômico de muitos países. Entretanto, com a realização dos diversos tipos de atividades que compõem o processo de exploração mineral, vários impactos negativos são gerados e, em algumas situações, estas ações são irreversíveis ao meio ambiente e, posteriormente, à população, ao ponto de ainda não terem sido completamente mensurados (BEZERRA, 2015).

Contudo, as indústrias de processamento $\mathrm{e}$ beneficiamento mineral se destacam pela quantidade de rejeitos produzidos, que está diretamente relacionado ao volume de produção, o que gera preocupação para ambientalistas, pesquisadores e a sociedade no geral, em virtude do aumento crescente da produção mineral nos últimos anos em todo o mundo (IPEA, 2012).

Segundo a Agência Nacional de Mineração, em 2018 a produção de caulim beneficiado no Brasil correspondeu a um total de 1,77 Mt, dos quais 90,6\% estão representados pelo estado do Pará. São Paulo possui a $2^{a}$ maior produção de caulim, seguido pelo Rio Grande do Sul.

No Nordeste, as reservas estão localizadas nos estados da Bahia, Paraíba, Pernambuco e Rio Grande do Norte, todas elas consideradas de pequeno porte. Existem pequenas minas na Província Pegmatítica da Borborema, que lavram caulins de pegmatito de melhor qualificação tecnológica e beneficiam por processo de concentração a úmido (decantação) (MME, 2009).

Seus principais usos são na produção do papel e na composição das pastas cerâmicas. Em menor escala, o caulim é utilizado na fabricação de materiais refratários, plásticos, borrachas, adesivos, cimentos, inseticidas, pesticidas, catalisadores, absorventes, dentifrícios, clarificantes, fertilizantes, gesso, tintas, auxiliares de filtração, cosméticos, produtos químicos, detergentes e abrasivos, produtos alimentares e farmacêuticos, além de cargas e enchimentos para diversas finalidades (SANTOS et al., 2018).

Outra grande preocupação está relacionada ao método de extração, no qual algumas mineradoras ainda adotam processos rudimentares com alto risco à segurança dos trabalhadores. A mineração de caulim subterrânea é incomum e no Brasil ocorre somente nos Estados do Rio Grande do Norte e da Paraíba, em minas de origem primária, onde o caulim ocorre em forma de coproduto, associado a outros minérios como os feldspatos, micas etc. $\mathrm{O}$ caulim naturalmente surge agregado a impurezas, e para atender às demandas do mercado, é necessário o seu beneficiamento, que pode acontecer por via seca ou via úmida (BRASIL, 2009).

O estudo de avaliação dos impactos ambientais é considerado no setor minerário de grande importância para a gestão ambientalmente correta, pois se não forem utilizadas de técnicas corretas, pode-se ocasionar graves danos ambientais, destacando os recursos hídricos superficiais, lençol freático e ao solo, além de causar intervenção negativa à comunidade circunvizinha, sendo considerada uma preocupação de caráter social.

A resolução CONAMA $n^{\circ}$ 1, de 23.01.1986, define Impacto Ambiental como:

Qualquer alteração das propriedades físicas, químicas e biológicas do meio ambiente, causada por qualquer forma de matéria ou energia resultante das atividades humanas que, direta ou indiretamente, afetam:

I - a saúde, a segurança e o bem-estar da população;

II - as atividades sociais e econômicas;

III - a biota;

IV - as condições estéticas e sanitárias do meio ambiente;

$\mathrm{V}$ - a qualidade dos recursos ambientais.

A exploração mineral deve atender aos requisitos (Licenciamento Ambiental) dos órgãos ambientais (IBAMA, DNPM, SUDEMA E IDEMA) e ser bem planejada. A perturbação ao meio depende de fatores como métodos de extração, técnicas utilizadas, natureza do minério, geologia, vulnerabilidade do meio ambiente local e resíduos produzidos (CASTILLA-GÓMEZ \& HERRERA-HERBERT, 2015). Dessa forma, é significativo identificar os impactos causados ao meio ambiente pela mineração, durante os processos de extração e beneficiamento de caulim.

Nesse sentido, a mineração é considerada uma atividade de grande impacto, porém, responsável pela movimentação da economia local e nacional, tornando-se fundamental analisar quais os impactos socioambientais da mineração de caulim sob o olhar das comunidades circunvizinhas, principalmente em 
relação ao descarte correto dos resíduos produzidos que prejudicam de forma negativa a saúde da população e a qualidade ambiental.

Diante disso, o objetivo deste trabalho é identificar os impactos ambientais causados nas atividades de extração e beneficiamento do caulim nos municípios do Junco do Seridó e Assunção na Paraíba e Equador no Rio Grande do Norte.

\section{MATERIAL E MÉTODOS \\ Caracterização da Área de Estudo}

$\mathrm{O}$ estudo abrangeu os municípios do Junco do Seridó e Assunção no Estado da Paraíba e Equador no Rio Grande do Norte (Figura 1). Estes municípios estão localizados na região mineradora denominada Província Pegmatítica Borborema-Seridó, a qual abrange os estados do Rio Grande do Norte e da Paraíba. Faz limite com os municípios paraibanos de Salgadinho, Assunção, Tenório, Santa Luzia e
Equador no Rio Grande do Norte (PRIVITERA, 2017).

Os municípios que foram avaliados pertencem à região denominada semiárido, que possui características e condições morfoclimáticas típicas do sertão, caracterizado por baixas precipitações e elevada temperatura, além da irregularidade das chuvas característica da região nordeste, tendo como resultado o clima seco e quente na maior parte do ano (SUDENE, 2017).

De acordo com o Instituto Brasileiro de Geografia e Estatística (IBGE, 2020), a população estimada de Equador-RN, é de 6.054 pessoas, no Junco do SeridóPB é de 7.195 e em Assunção-PB é de 4.029 pessoas, já em relação ao Índice de Desenvolvimento Humano Municipal (IDHM), Equador-RN é de 0,623, Junco do Seridó-PB é de 0,617 e em Assunção é de 0,609, baseado no censo de 2010 .

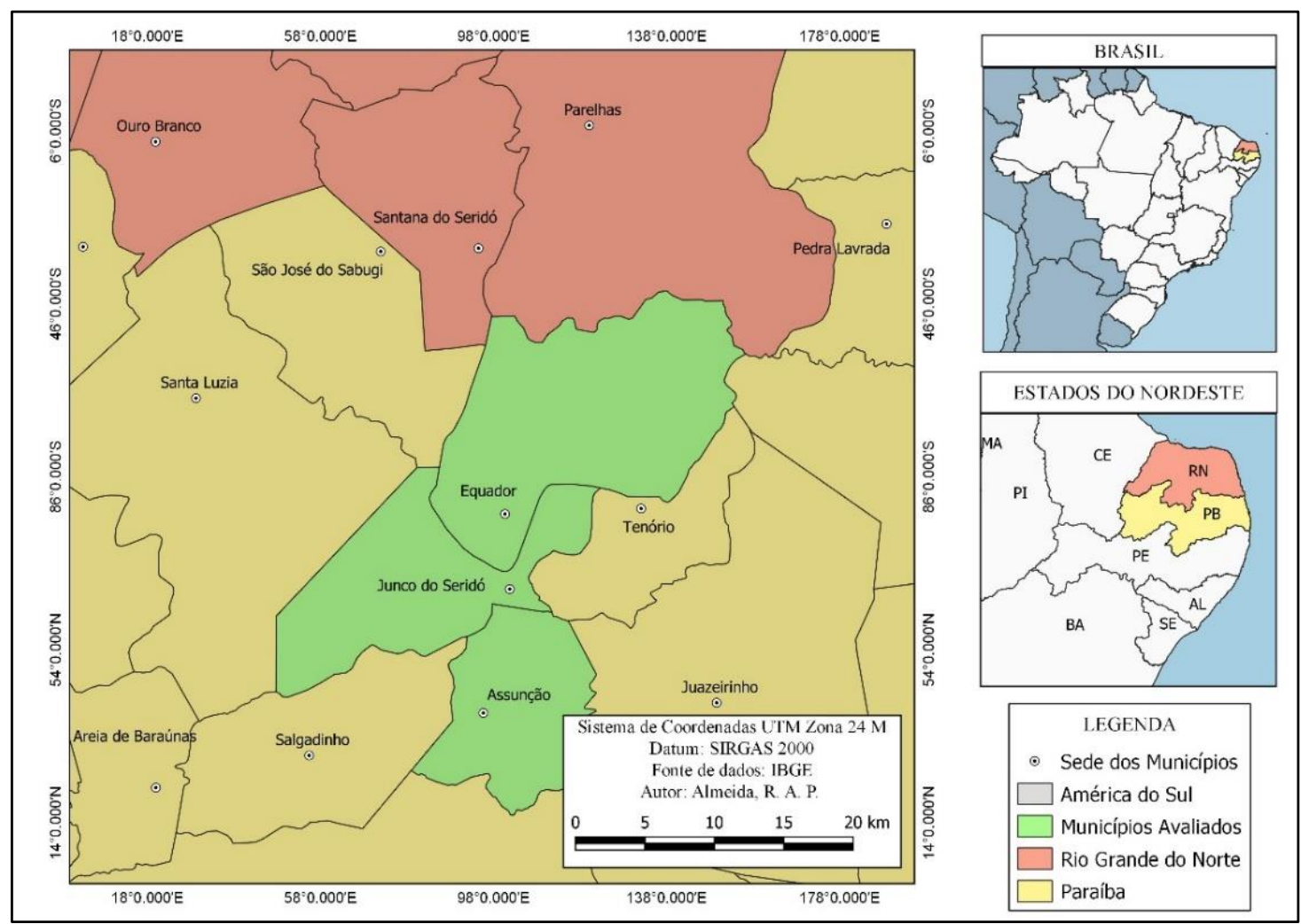

Figura 1. Mapa de localização dos municípios avaliados com relação aos impactos socioambientais da mineração de caulim nas comunidades circunvizinhas.

Fonte: do Autor, Paraíba, 2020.

\section{Coleta de Dados}

O presente trabalho utilizou da técnica de Análise de conteúdo proposta por Bardin (2011), baseado na aplicação dos questionários, classificando-se como uma pesquisa de campo qualitativa e quantitativa. Os questionários semiestruturados foram aplicados nas comunidades rurais circunvizinhas, em um raio de até cinco quilômetros da região com maior quantidade de mineradoras de caulim de cada município (Figura 2).
Para delimitação da área de estudo e baseado no conhecimento prévio das áreas pelo auto desse trabalho, foi realizada uma análise prévia utilizando imagens de satélite do Google Earth, verificando os locais próximos das serras, nos quais ocorrem a extração e as áreas que apresentavam um perímetro na cor branca, ocasionada pela distribuição do caulim nas áreas onde ocorre o beneficiamento, onde possuem as pilhas com matéria prima bruta e o rejeito. 


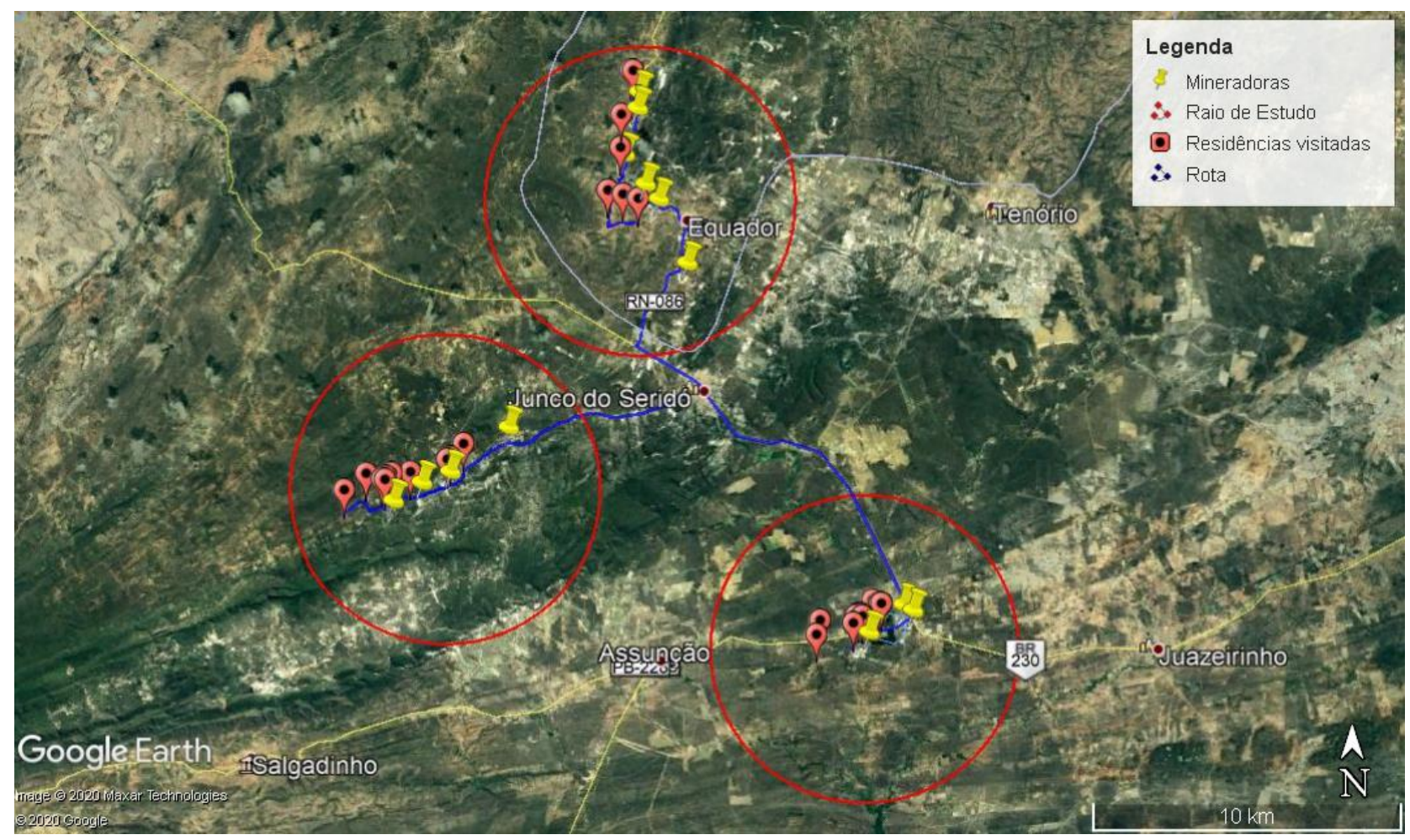

Figura 2. Croqui de localização da área de estudo, das mineradoras de caulim e das residências visitadas para aplicação do questionário semiestruturado.

Fonte: Adaptado do Google Earth, 2020.

O trabalho foi submetido ao Comitê de Ética em Pesquisa - CEP em 10/12/2019, de $n^{\circ}$ 26801419.7.0000.5575, respeitando todos os princípios, direitos e normas dos participantes da pesquisa, tendo os participantes assinado o Termo de Consentimento Livre e Esclarecido - TCLE. Nesse sentido, os interlocutores que participaram da pesquisa concordaram de forma voluntária.

Tendo em vista que a pesquisa foi realizada com moradores da zona rural que geralmente estão bastante ocupados com o trabalho na roça, foi elaborado um número médio de questões para que assim a entrevista não se tornasse cansativa. As perguntas abordaram de maneira sucinta e integrada os principais assuntos (Meios físico, Biótico e Antrópico), de interesse sobre o tema abordado (Apêndice A - Bloco 3). Foram estimadas realizar, no mínimo, 30 entrevistas; como o público alvo seria moradores da zona rural, não havia como definir uma amostra exata, devido algumas casas estarem abandonadas e outras fechadas no momento da visita.

Optou-se por não realizar a aplicação do questionário com os funcionários das empresas devido as respostas dos mesmos poderem ser influenciadas por proprietários e/ou gerentes do empreendimento; sendo assim, o questionário foi aplicado apenas com a população rural circunvizinha.

\section{Análise dos Dados}

Considerando-se os impactos ambientais da mineração de caulim sobre os Meios Físico (ar, água e solo), Biótico (fauna e flora) e Antrópico (social, econômico e saúde), a análise dos dados coletados foi feita através de planilha eletrônica e imagens de satélite, estabelecendo como limite o raio de $5 \mathrm{~km}$ ao entorno das áreas de mineração e processamento. Para verificar as informações obtidas pelas entrevistas foi adotada a técnica de Análise de Conteúdo e interpretação. A fim de otimizar o tempo de coleta de dados em campo, foi feita uma análise prévia dos possíveis domicílios existentes próximos das mineradoras com o software Google Earth, através de imagens de satélite.

\section{RESULTADOS E DISCUSSÃO}

Ao todo foram aplicados 30 questionários: 11 no município do Junco do Seridó-PB, 10 em AssunçãoPB e 9 em Equador-RN; em outras 20 residências, algumas pessoas se negaram a participar; outras estavam fechadas no momento da visita ou estavam abandonadas, totalizando 50 domicílios visitados. Das residências onde houve aplicação do questionário, $60 \%$ eram isoladas e outras $40 \%$ em comunidades.

Dentre os 30 interlocutores, 11 eram do sexo masculino e 19 do sexo feminino, com idade entre 27 e 66 anos. Quanto à escolaridade dos interlocutores, $20 \%$ possuem o ensino fundamental completo, $40 \%$ ensino fundamental incompleto, $20 \%$ ensino médio completo e os outros $20 \%$ variaram entre analfabetos, ensino superior completo e incompleto.

Quanto ao estado civil 86,7\% eram casados e $13,3 \%$ eram solteiros. Com relação à quantidade de 
pessoas morando no domicílio, variou de 1 a 8 pessoas, no qual 3 pessoas obtiveram a maior frequência, chegando a 33,3\%. No aspecto fontes de água existente na casa, $60 \%$ respondeu ter poço artesiano, 56,7\% cisterna, 53,3\% água encanada, $23,3 \%$ carro pipa e apenas $16,7 \%$ de açude.

Quando perguntados por qual meio de comunicação tinham acesso às informações ambientais, $73,3 \%$ respondeu que através da televisão, 43,3\% pela internet, $33,3 \%$ pelo jornal, $30,0 \%$ rádio e apenas $23,3 \%$ na escola.

Os moradores apresentaram uma renda mensal variando de meio a dois salários mínimos por família.
Dos interlocutores, $43,3 \%$ tinham como principal fonte de renda a agricultura, 26,7\% eram aposentados, $10,0 \%$ trabalhavam de forma autônoma, apenas $10,0 \%$ trabalhavam na mineração e 46,7\% possuíam algum familiar trabalhando na mineração, 10,0\% detinham como principal fonte de renda projetos sociais do governo, como: auxílio emergencial e bolsa família.

Os resultados das respostas ao questionário (Bloco 2 - Percepção dos impactos ambientais) estão expressos na tabela 1 e ilustrados na figura 3 .

Tabela 1. Respostas dos entrevistados com relação aos principais aspectos e impactos ambientais da atividade de mineração de caulim. Patos-PB. 2020.

\begin{tabular}{|c|c|c|c|c|c|}
\hline \multirow{2}{*}{ Componentes } & \multirow{2}{*}{ Aspectos } & \multicolumn{4}{|c|}{ Respostas (\%) } \\
\hline & & Sim & Em parte & Não & Não sei \\
\hline \multirow{3}{*}{ Solo } & Perda na Qualidade do solo & 43 & 0 & 43 & 13 \\
\hline & Erosão & 33 & 7 & 50 & 10 \\
\hline & Poeira & 43 & 10 & 43 & 3 \\
\hline Som & Poluição sonora & 20 & 7 & 70 & 3 \\
\hline \multirow{3}{*}{ Água } & Perca na Qualidade da água & 20 & 10 & 70 & 0 \\
\hline & Assoreamento & 37 & 3 & 47 & 13 \\
\hline & Recursos hídricos diminuindo & 37 & 7 & 57 & 0 \\
\hline \multirow{3}{*}{ Vegetação } & Desmatamento & 53 & 13 & 33 & 0 \\
\hline & Desaparecimento de espécies da flora & 40 & 3 & 47 & 10 \\
\hline & Flora Prejudicada & 57 & 3 & 33 & 7 \\
\hline \multirow{3}{*}{ Fauna } & Deslocamento da fauna & 33 & 13 & 37 & 17 \\
\hline & Desaparecimento de espécies da fauna & 40 & 3 & 33 & 23 \\
\hline & Diminuição da população da fauna & 40 & 10 & 27 & 23 \\
\hline \multirow{2}{*}{ Social } & Conflitos de terra & 13 & 3 & 73 & 10 \\
\hline & Conflitos sociais & 10 & 10 & 73 & 7 \\
\hline \multirow{3}{*}{ Econômico } & Geração de empregos & 70 & 10 & 17 & 3 \\
\hline & Melhoria no comércio local & 57 & 17 & 20 & 7 \\
\hline & Melhoria da renda familiar & 60 & 7 & 30 & 3 \\
\hline \multirow{2}{*}{ Saúde } & Acidentes na mineração & 23 & 0 & 63 & 13 \\
\hline & Problemas de saúde & 33 & 3 & 63 & 0 \\
\hline
\end{tabular}

Entre os impactos que mais afetam a população circunvizinha 53,3\% dos entrevistados afirmaram que a poeira incomodava devido, principalmente, ao acúmulo de rejeito e de matéria prima utilizada pelas mineradoras, os quais acabam ficando espalhados nas estradas e, com trânsito frequente de veículos, afetam a população.

De acordo com Privitera (2017) durante o processo de beneficiamento, o rejeito é descartado sem nenhum tipo de tratamento, causando danos irreversíveis ao meio ambiente, no qual o rejeito se transforma em pó e se espalha pela ação do vento e da chuva, poluindo o ar, os recursos hídricos, a vegetação, afetando a população. Segundo Lima (2010) o processo de beneficiamento de caulim em mineradoras de porte médio, no município de Equador-RN, gera em média 1100 toneladas de resíduos mensais. De acordo com Andrade \& Azevedo (2015), o caulim é transportado seco e sem proteção. Ao ser transportado, a ação do vento o dispersa no entorno, poluindo $\mathrm{o}$ ar $\mathrm{e}$ prejudicando todo o trajeto, além de grande quantidade de material na área onde as banquetas estão em atividade afetando, dessa forma, os garimpeiros e as comunidades do entorno.

A fim de ilustrar o resultado da aplicação do questionário estruturado, elaborou-se a Figura 3, apresentando a porcentagem de resposta de cada aspecto mostrado na tabela acima, possibilitando uma análise comparativa. 
n Sim Em parte $\quad$ Não $\quad$ Não sei

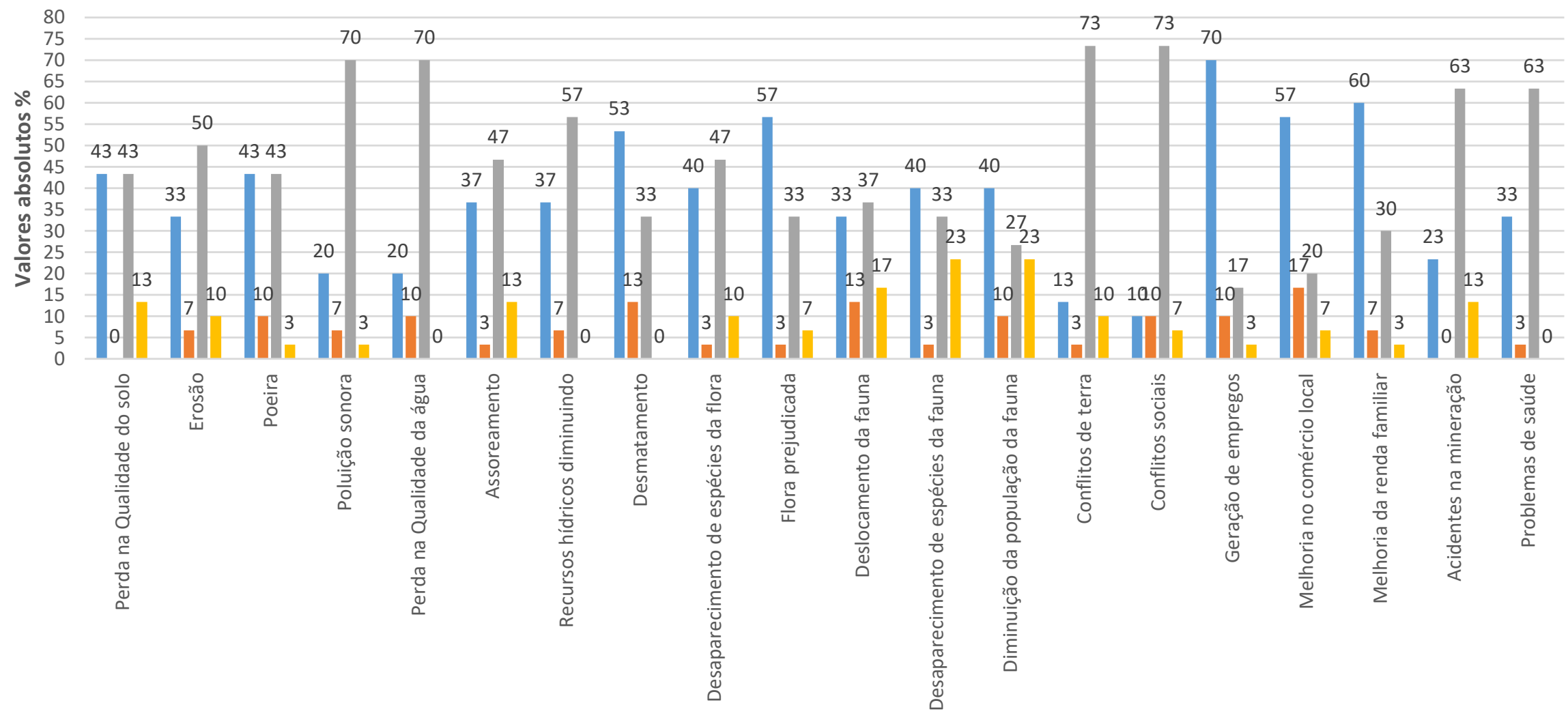

Aspectos

Figura 3. Resultado geral do Bloco 3 do questionário semiestruturado aplicado nas comunidades circunvizinhas às mineradoras de caulim. Patos-PB. 2020. 
Quando questionados sobre a poluição sonora, $26,7 \%$ dos interlocutores declararam estar sendo prejudicados por proximidade às mineradoras ou minas. No componente solo, $43,3 \%$ acreditam que está havendo perda na qualidade do solo; $40,0 \%$ alegaram estar ocorrendo assoreamento e erosão em alguns locais. Já no componente água, 30,0\% relataram perda na qualidade da água e $43,3 \%$ apontaram para a diminuição dos recursos hídricos, tendo em vista que a mineração utiliza-se de uma grande quantidade de água durante o processo de beneficiamento. Essa informação é corroborada no item aspectos "fontes de água existente na casa", onde $60 \%$ respondeu ter poço artesiano, 56,7\% cisterna, 53,3\% água encanada, 23,3\% carro pipa e apenas 16,7\% de açude. Bressane et al., (2015), demonstraram em seus estudos que as atividades de mineração são modificadoras do meio ambiente e acarretam impactos significativos sobre a comunidade onde se inserem.

Com relação à vegetação, sendo considerado o aspecto mais grave, $66,7 \%$ dos interlocutores afirmaram que vem ocorrendo desmatamento na região, 43,3\% acreditam que já desapareceu alguma espécie e $60 \%$ supõem que a vegetação está sendo prejudicada. Andrade et al. (2015), ressaltam que a queima de madeira para a secagem do caulim nos fornos, quando os dias estão muito úmidos ou chuvosos, além da poluição atmosférica, causa sérios prejuízos à flora e fauna nativa.

Com respeito à fauna silvestre, $46,7 \%$ acreditam ocorrer o deslocamento dos animais para outros locais, $43,3 \%$ relataram o desaparecimento de espécies e $50 \%$ pressupõem que há uma diminuição na população. Essa perda deve-se principalmente ao desmatamento realizado para atender os fornos das mineradoras e para utilização da comunidade do entorno que ainda utiliza a madeira para cozinhar ou em outras atividades domésticas. Outro aspecto que leva ao deslocamento dos animais é a questão das explosões realizadas nas minas no processo de extração do caulim bruto, como também o tráfego de veículos pesados. Andrade \& Azevedo (2015), enfatizam que em relação à fauna típica da região, as áreas mais distantes da zona rural e de altitudes elevadas, é onde se encontram as espécies em melhores condições de preservação, em maior número e diversidade de espécies. Os autores ainda ressaltam que são, em geral, os animais que fugiram das áreas mais próximas das banquetas e das mineradoras. Esses animais buscam áreas mais úmidas, mais protegidas e que possam se abrigar nas árvores.

No aspecto social, $73 \%$ dos interlocutores negaram possuir algum tipo de conflito social ou de terra. Em relação aos acidentes de trabalho na mineração $63 \%$ responderam que não. Em contrapartida, $80,0 \%$ declararam ter ocorrido um aumento na geração de empregos após a chegada das mineradoras, $73,3 \%$ informaram que melhorou o comércio local e $66,7 \%$ tiveram um aumento na renda familiar, anteriormente dependentes de projetos socias do governo ou que viviam exclusivamente da agricultura. Segundo Privitera (2017), nesta região é muito comum a garimpagem como processo de extração dos minerais como o caulim, e é por meio dos garimpos que muitas famílias sobrevivem. A atividade de mineração do caulim na região do Seridó é uma atividade de pequeno porte e fragmentada, uma atividade rudimentar, com limitado acesso à tecnologia, promovendo alto risco aos trabalhadores e contínuos impactos ao meio ambiente. No entanto, é uma atividade importante para a região por empregar mão-de-obra local (BRASIL, 2014). De acordo com Morais (2018), a maior parte dos garimpeiros são até certo ponto alfabetizados, em nível básico; no entanto, acabam optando pelo trabalho nas mineradoras, pois muitas vezes falta oportunidade de continuar os estudos, casam precocemente e pertencem a famílias extremamente pobres. No entanto, o que resta é apenas se dedicar ao trabalho nas banquetas ou galerias de caulim.

No aspecto saúde $23,3 \%$ relataram já ter ouvido falar em algum tipo de acidente nas atividades minerárias e 36,7\% informaram ter algum problema de saúde, entre os mais citados estão: asma, gripe, sinusite, hipertensão. De acordo com Cabral et al., (2009) devido ao caulim possuir partículas sólidas muito pequenas, a exposição durante um longo período pode provocar doenças no sistema respiratório dos trabalhadores, como a silicose, e levá-los até a morte. Então, os dados do presente trabalho corroboram com o que esses autores afirmaram.

\section{CONCLUSÕES}

Os interlocutores demonstraram, através da vivência cotidiana, sentir e conhecer parte dos problemas e impactos causados pela mineração de caulim, em especial os incômodos causados pela poeira. Eles relatam problemas respiratórios como asma e sinusite, mas não os correlacionam com a mineração, mas a literatura confirma que este tipo de atividade pode levar a doenças como estas. Verificou-se que as respostas foram muito semelhantes nos diferentes municípios, mostrando que os impactos causados e a percepção dos moradores são similares. Nesse sentido, pode-se inferir que o baixo grau de escolaridade pode estar contribuindo para que não haja essa percepção de correlacionar o problema da poeira e respectivos problemas respiratórios. 
No tocante ao meio ambiente, os interlocutores conseguem identificar a intensificação do desmatamento, erosão, diminuição de recursos hídricos, desparecimento de espécies da flora e fauna.

No cenário atual, a mineração do caulim nos municípios avaliados tem o predomínio de empreendimentos de pequeno porte, muitos clandestinos, executados de forma rudimentar, com mão de obra garimpeira barata e sem qualificação. Nesse sentido, mesmo gerando aspectos positivos como aqueles relatados pelos interlocutores como mais empregos, melhoria do comércio e renda, salienta-se que esses empregos são degradantes do ponto de vista físico e de saúde, bem como proporciona uma baixa renda à comunidade envolvida.

Concluindo, há de se questionar que as relações entre sociedade e natureza nos territórios estudados tende a se apresentar de forma negativa aos dois componentes: sociedade e natureza.

\section{REFERENCIAS}

AGÊNCIA NACIONAL DE MINERAÇÃO - ANM. Sumário mineral 2018 (ano base 2017). 2018. Disponível em: https://www.gov.br/anm/pt-br/centraisde-conteudo/publicacoes/serie-estatisticas-e-economiamineral/sumario-mineral/pasta-sumario-brasileiromineral-2018/caulim_sm_2018. Acesso em 18 ago. 2020 .

ANDRADE, A. L. S., et al. Mineração de caulim no município de Equador-RN Brasil: andragogia e percepção ambiental. Revista Brasileira de Gestão Ambiental GVAA - Grupo Verde de Agroecologia e Abelhas, Pombal-PB, v. 9, p. 27-47, 2015. Disponível em:

https://www.gvaa.com.br/revista/index.php/RBGA/arti cle/view/4797/4127. Acesso em 18 ago. 2020.

ANDRADE, M. V.; AZEVEDO, P. V. Analise da Sustentabilidade da Mineração do Caulim no Município de Junco do Seridó-PB. Revista Brasileira de Geografia Física, v. 8, n. 5, p. 1393-1409, 2015. Disponível em: https://periodicos.ufpe.br/revistas/rbgfe/article/view/23 3470/27161. Acesso em 18 ago. 2020.

BARDIN, L. Análise de conteúdo. São Paulo: Edições 70, 2011, 229 p.

BEZERRA, L. M. A. Análise dos impactos socioambientais decorrentes da mineração na chapada do Araripe, Nova Olinda, Ceará. Geosaberes, Fortaleza, v. 6, n. 2, p. 79 - 89, jul. 2015. Disponível em: http://www.geosaberes.ufc.br/geosaberes/article/view/4 13/378. Acesso em 19 ago. 2020.

BOMFIM, M. R. Avaliação de Impactos Ambientais da Atividade Minerária. Especialização de Mineração e Meio Ambiente. Cruz das Almas - BA: Universidade
Federal do Recôncavo da Bahia (UFRB), 2017. Disponível em: https://educapes.capes.gov.br/bitstream/capes/175229/1 /avaliacao.pdf. Acesso em 20 ago. 2020.

BRASIL. Departamento Nacional de Produção Mineral - DNPM. Sumário Mineral 2014. 141 p. Disponível em:

http://antigo.anm.gov.br/portal/dnpm/sumarios/sumario -mineral-2014/view. Acesso em 20 ago. 2020.

BRESSANE, A. M., et al. Abordagem construtivista integrando o ensino, a pesquisa e a aplicação à realidade: o caso da pós-graduação em Ciências Ambientais da Unesp Sorocaba. RBPG, Brasília, v. 12, n. 27, p. 251 276, 2015. Disponível em: http://ojs.rbpg.capes.gov.br/index.php/rbpg/article/view /677/pdf. Acesso em 21 ago. 2020.

CABRAL, E. da S., et al. IMPACTOS AMBIENTAIS: Uma Abordagem das Atividades de Beneficiamento de Caulim na Região Borborema/Seridó na Paraíba. Centro Científico Conhecer - ENCICLOPÉDIA BIOSFERA, Goiania, v. 5. 2009. Disponível em: http://docplayer.com.br/storage/25/5676301/16061637 50/gxIyXkW1wQOyBHjtbv9UKw/5676301.pdf.

Acesso em 26 ago. 2020.

CASTILLA-GÓMEZ, J.; HERRERA-HERBERT, J. Environmental analysis of mining operations: Dynamic tools for impact assessment. Minerals Engineering, v. 76, p. 87-96, 2015.

CONAMA - Conselho Nacional do Meio Ambiente. Resolução no $^{\circ}$, de 23 de janeiro de 1986. Dispõe sobre critérios básicos e diretrizes gerais para a avaliação de Impacto Ambiental - AIA. Brasília: DOU de 17/02/1986.

INSTITUTO DE PESQUISA ECONÔMICA APLICADA - IPEA. Diagnóstico dos Resíduos Sólidos da Atividade de Mineração de Substâncias Não Energéticas: Relatório de Pesquisa. Brasília, 2012. Disponível em: http://repositorio.ipea.gov.br/bitstream/11058/7702/1/R P_Diagn\%C3\%B3stico_2012.pdf. Acesso em 24 ago. 2020 .

LIMA, R. do C. de O. Diagnóstico dos impactos ambientais decorrentes do beneficiamento de caulim no município de Equador - RN. Revista de Biologia e Ciências da Terra. Vol. 10 - Número 2 - $2^{\circ}$ Semestre $2010 . \quad$ Disponível em: https://www.redalyc.org/pdf/500/50016922010.pdf. Acesso em 26 ago. 2020.

MINISTÉRIO DE MINAS E ENERGIA - MME; Secretaria de Geologia, Mineração e Transformação Mineral - SGM. Banco Mundial. Banco Internacional para a reconstrução e desenvolvimento - BIRD. Relatório Técnico 39: Perfil do Caulim. 2009. 61 p. Disponível em: http://www.jmendo.com.br/wpcontent/uploads/2011/08/P28_RT39_Perfil_do_Caulim .pdf. Acesso em 24 ago. 2020. 
MINISTÉRIO DE MINAS E ENERGIA - MME. Boletim do setor mineral. $2^{\text {a }}$ ed. 2019.

MORAIS, J. de. As relações de trabalho na produção de caulim no município de Equador-RN. Trabalho de conclusão de curso. Universidade Estadual da Paraíba UEPB. Campina Grande. 43 p. 2018. Disponível em: http://dspace.bc.uepb.edu.br/jspui/bitstream/123456789 /17802/1/PDF\%20-

$\% 20 \mathrm{Jos} \% \mathrm{C} 3 \%$ A9lia\%20de\%20Morais.pdf. Acesso em 01 set. 2020.

PRIVITERA, A. D. Exploração mineral no Seridó Paraibano: a desigualdade e as relações de trabalho por trás da exploração do Caulim em Junco do Seridó (PB). 2017. 71 f. TCC (Graduação) - Curso de Geografia, Faculdade de Filosofia, Letras e Ciências Humanas da Universidade de São Paulo, São Paulo, $2017 . \quad$ Disponível em: http://www.tcc.sc.usp.br/tce/disponiveis/8/8021101/tce -26062017-

185409/publico/2017_ArianeDantasPrivitera.pdf. Acesso em 01 set. 2020.
SANTOS, J. P. de O., et al. Resíduos Sólidos: impactos socioeconômicos e ambientais. 1. ed. Recife: EDUFRPE, 2018. 579 p. Disponível em: http://www.editora.ufrpe.br/Epersol_impacto. Acesso em 01 set. 2020.

SUPERINTENDÊNCIA DO DESENVOLVIMENTO DO NORDESTE - SUDENE. Delimitação do semiárido. Resolução $\mathrm{N}^{\mathrm{o}} 115$, de 23 de novembro de 2017. Brasília: DOU de 05/12/2017. 